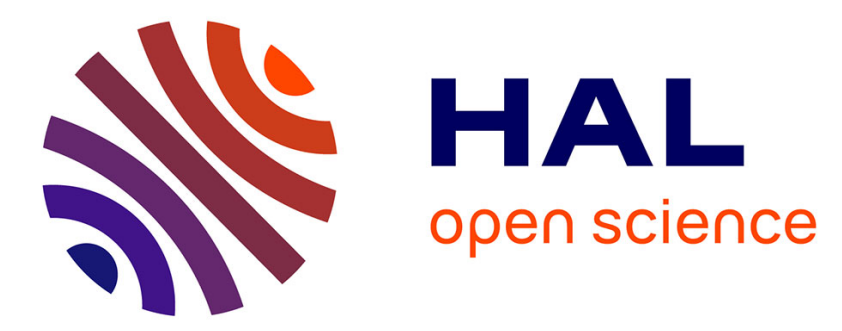

\title{
Structural transformations in TTAB aggregated binary systems
}

\author{
R. Yadav, Ph. Khani, P. Jain
}

\section{To cite this version:}

R. Yadav, Ph. Khani, P. Jain. Structural transformations in TTAB aggregated binary systems. Journal de Physique IV Proceedings, 1993, 03 (C4), pp.C4-333-C4-335. 10.1051/jp4:1993455 . jpa00251498

\section{HAL Id: jpa-00251498 https://hal.science/jpa-00251498}

Submitted on 1 Jan 1993

HAL is a multi-disciplinary open access archive for the deposit and dissemination of scientific research documents, whether they are published or not. The documents may come from teaching and research institutions in France or abroad, or from public or private research centers.
L'archive ouverte pluridisciplinaire HAL, est destinée au dépôt et à la diffusion de documents scientifiques de niveau recherche, publiés ou non, émanant des établissements d'enseignement et de recherche français ou étrangers, des laboratoires publics ou privés. 


\title{
Structural transformations in TTAB aggregated binary systems
}

\author{
R. YADAV, P.H. KHANI and P.C. JAIN
}

Department of Physics \& Astrophysics, University of Delhi, Delhi 110 007, India

\begin{abstract}
Structural transformations in TTAB aggregated systems have been investigated using positron lifetime spectroscopy. Positron lifetime measurements have been carried in TTAB/water and TTAB/pentanol binary solutions as a function of surfactant concentration. In TTAB/water, molecular aggregation sets in at a surfactant concentration of $\sim 3.5 \mathrm{mM}(\mathrm{CMC})$. Several changes in micellar structure as a function of surfactant concentration are indicated. In TTAB/pentanol binary solutions, evidence for molecular aggregation is seen. With increasing surfactant concentration other structural transformations are indicated.
\end{abstract}

\section{Introduction}

The cationic surfactants of general formula $\mathrm{RN}\left(\mathrm{CH}_{3}\right)_{3} \mathrm{X}$, where $\mathrm{R}$ is an alkyl chain and $\mathrm{X}$ an anion, have interesting properties. The physico-chemical properties of these surfactants are largely determined by the nature of the counterion and the alkyl chain length[1-5]. Of this class of amphiphils, cetyl trimethyl ammonium bromide(CTAB) has been investigated thoroughly. Recently, detailed positron annihilation studies have been carried out in CTAB/water/hexanol system[6,7]. These have revealed interesting structural details of several phases exhibited by this system. Tetra decyl trimethyl ammonium bromide(TTAB) is a lower homologue of CTAB, information about its behaviour is rather meagre[3,8-10]. A detailed study of the phase equilibria in TTAB/water/ pentanol is lacking. Such a study has, therefore, been undertaken. Considering the sensitivity of the positron annihilation parameters to structural and phase transformations occurring in a system, positron lifetime spectroscopy has been employed. However, other techniques have also been used to provide supporting evidences. In this paper, we present the results obtained in TTAB/water and TTAB/pentanol binary solutions.

\section{Experimental}

TTAB and pentanol having purities better than $98 \%$ were procured from Fluka AG and were used without any further purificaton. Deionised triple distilled water was used for making various aqueous solutions. Positron lifetime measurements were carried out using a standard lifetime spectrometer. Positron source used was ${ }^{22} \mathrm{Na}$. It was prepared by evaporating few drops of an aqueous solution of ${ }^{22} \mathrm{NaCl}$ on a thin $\mathrm{Mylar}$ film and then covering it by another similar film. The source sandwich was sealed by using a special grade epoxy resin. The sealed source was kept in a specially designed sample holder. Positron lifetime measurements were perfomed in TTAB/water and TTAB/ pentanol binary solutions as a function of the surfactant concentration. All measurements were ${ }_{5}$ performed at room temperature. In each set of measurements a minimum of $2 \times 10^{5}$ counts were collected. 


\section{Results and discussion}

The lifetime spectra obtained were analysed using a software PC-PATFIT, developed by Riso National Laboratory[11]. Details of the data analysis procedure adopted are described elsewhere[12]. All the lifetime spectra could be decomposed into three components. The shortest component, $\tau_{1}$, was constrained to p-Ps lifetime. The other two components, $\tau_{2}$ and $\tau_{3}$, were attributed to free annihilations of positrons and o-Ps pick-off annihilation, respectively. The relative intensity, $I_{3}$, of the longest component is, therefore, proportional to Ps formation probability. The parameters $\tau_{3}$ and $I_{3}$ exhibit considerable sensitivity to various structural and phase transformations occurring in the medium.

The results obtained in the two systems investigated are shown in Figures 1 and 2 . These depict the dependence of $\tau_{3}$ and $I_{3}$ values on the surfactant concentration in TTAB/water and TTAB/pentanol systems, respectively. The results obtained in TTAB/water system (Fig. 1) are similar to those obtained in CTAB/water solutions. On the basis of observed changes in $\tau_{3}$ and $I_{3}$, the plot in Figure 1 can be divided into five distinct regions marked I- $V$. These regions depict different stages of molecular aggregation. The region $I$ is characterised by near constancy of $\tau_{3}$ and $\mathrm{I}_{3}$ indicating that in the monomeric form the Ps formation and o-Ps pickoff annihilation are not affected by surfactant concentration. An abrupt drop in the value of $\mathrm{I}_{3}$ occurs at a surfactant concentration of $3.6 \mathrm{mM}$, it indicates the onset of molecular aggregation. The molar conductivity measured in these solutions also decreases abruptly at this surfactant concentration. Thus on the basis of positron lifetime and molar conductivity measurements, the CMC for TTAB in water is found to be $3.6 \mathrm{mM}$, it agrees with the $\mathrm{CMC}$ reported in literature[3]. The CMC of TTAB in water is thus found to be higher than that of CTAB in water, this indicates that with increasing alkyl chain length, the CMC of this class of surfactants in water decreases.

At the end of region I, on increasing the surfactant concentration the $\mathrm{I}_{3}$ value first decreases, attaining a minimum at 4.5 $\mathrm{mM}$ and then begins to increase. It attains a maximum value at a surfactant concentration of $5.0 \mathrm{mM}$ and then begins to decrease gradually. Correspondingly the $\tau_{3}$ value shows an opposite behaviour. This behaviour is different from that of CTAB

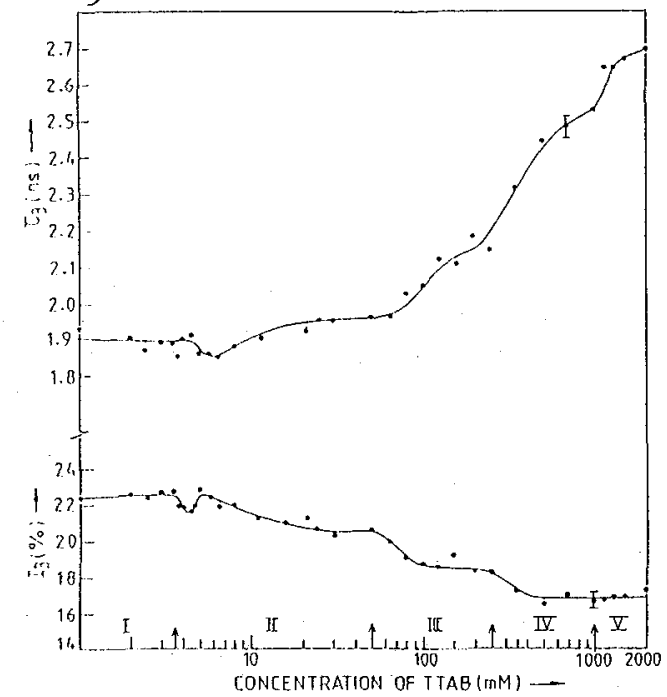

Fig.1: Dependence of $\tau_{3}$ and $I_{3}$ on surfactant concentration in TTAB/water binary system.

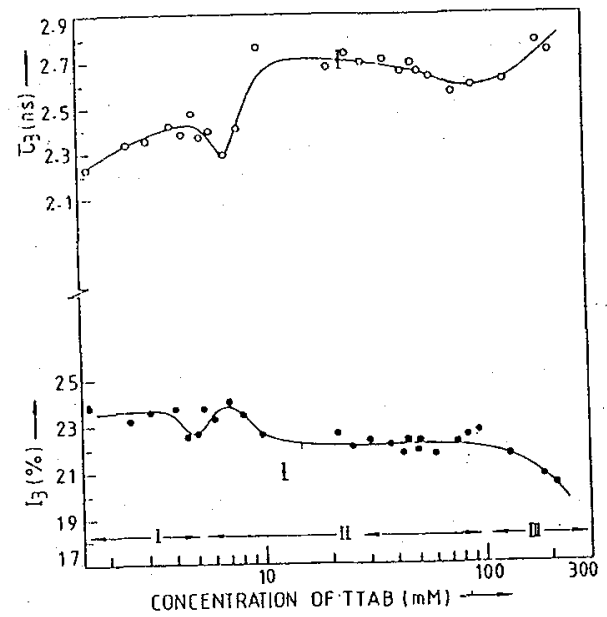

Fig.2: dependence of $\tau_{3}$ and $I_{3}$ on surfactant concentration in TTAB/pentanol binary system. 
in water. In these solutions, on initiation of molecular aggregation there is a competition between the number and size of micelles. On increasing the surfactant concentration, both the parameters begin to grow; soon the size or the aggregation number attains an optimum value. Further addition of surfactant leads to an increase in the concentration of aggregates. After a certain concentration of the micelles is reached, the intermicellar interaction becomes important leading to their deformation. In TTAB/water solutions since the CMC is high and the aggregation number is low, just after CMC, i.e. in the surfactant concentration range 3.7-8.0 $\mathrm{mM}$, the system is in an unstable state which is reflected by the dip in $\mathrm{I}_{3}$ value. Thus in these solutions, even just after the CMC the micelles are deformed which increases with increasing surfactant concentration leading to a gradual decrease in $\mathrm{I}_{3}$ value. This behaviour of the system is represented by the region II.

At the boundary of region II, a further drop in $\mathrm{I}_{3}$ value is observed indicating a structural change. At this stage the deformation of the micelles has become large leading to instability of their structure and a transformation from extended to rod like micelles is initiated. Further addition of surfactant completes the change which is indicated by near constancy of $\mathrm{I}_{3}$ in region III. Further addition of surfactant leads to an increase in the concentration of rod like micelles. At a certain stage they begin to overlap leading to their entanglement. According to Imae and Ikeda[13] such a situation is expected at a surfactant concentration of $\sim 250 \mathrm{mM}$ which agrees with the bouandry between the regions III and IV. Thus the region IV represents the entangled rod like structure of micelles. At a surfactant concentration of $\sim 1000 \mathrm{mM}$ or $32 \%$ by weight a transformation to hexagonal liquid crystalline structure occurs. This change is better indicated by an abrupt change in $\tau_{3}$ value.

The dependence of $\tau_{3}$ and $I_{3}$ values on surfactant concentration in TTAB/pentanol binary solutions is shown in Figure 2 . It is seen that these parameters undergo marked changes with increasing surfactant concentration suggesting some structural changes occurring in the system. The setting in of molecular aggregation is clearly indicated at a surfactant concentration of about $4 \mathrm{mM}$. With increasing surfactant concentration, other changes in micellar structure are indicated.

The present investigation carried out in TTAB/water and TTAB/pentanol systems illustrates the usefulness of positron lifetime spectroscopy in revealing structural changes occurring in such systems. In TTAB/water system, the structural transformations from nearly spherical to rod like and then entangled rod like structures are clearly indicated.

\section{References}

/1/ HUSSON, F R and LUZZATI, v, J. Phys. Chem.60(1964)3504.

/2/ EKWALL, P, MANDELL, L and FONTELL, K, J. Colloid Int. Sci. 29(1969)639.

13/ ZANA, R, J. Colloid Int. Sci. 78(1980)330.

/4/ BERR, S, J. Phys. Chem. 91(1987)4760.

15/ BERR, S, JONES, R R M and JOHNSON, J S, J. Phys. Chem. 96(1992)5611.

16/ ROY CHOUDHURY, S, Ph.D. Thesis, Delhi University, 1991.

$17 /$ ROY CHOUDHURY, S, YADAV, R, MAITRA, A N and JAIN, P C, Colloid and Surfaces (in press).

18/ BRAGANZA, L F, DUBOIC, M and TABONY, J, Nature 403(1989)338.

19/ FRIBERG, S E, VENABLE, R L, KIM, $M$ and NEOGI, P, Colloid and Surfaces 15 (1985)285.

/10/ KHANI, P H, MAITRA, A N and JAIN, P C, (to be published).

/11/ KIRKEGAARD, P, PEDERSEN, $\mathrm{N} J$ and ELDRUP, $M$, Report No. Riso-M-2740, Riso National Laboratory, Denmark, 1989.

/12/ YADAV, R, Ph.D. Thesis, Delhi University, 1993.

/13/ IMAE, T and IKEDA, S, J. Phys. Chem. 90(1986)5216. 